\title{
Penentuan Kebutuhan Injeksi Ammonia untuk Meningkatkan pH pada Air Umpan Boiler: Studi Kasus di PT. XYZ Sumatera Utara
}

\author{
Dimas Frananta Simatupang ${ }^{* 1}$, Ramadhani² \\ ${ }^{1,2}$ Program Studi Teknik Kimia, Politeknik Teknologi Kimia Industri Medan, Indonesia \\ Email: 1difratas@ptki.ac.id, ${ }^{2}$ dhanitampubolon9@gmail.com
}

\begin{abstract}
Abstrak
Air umpan boiler di PT. XYZ berasal dari air laut. Pengolahan air laut menjadi air umpan boiler melewati beberapa tahapan dengan tujuan untuk menghilangkan pengotor, kadar garam, ion-ion dan gas terlarut yang ada pada air laut. Salah satu parameter mutu air umpan boiler adalah memiliki pH dengan standar pabrik 9,2-9,6. pH yang tidak memenuhi standar pabrik dapat menyebabkan korosi pada pipa dan boiler. Untuk mencapai pH yang sesuai dengan standar pabrik maka harus dilakukan treatment lanjutan berupa penambahan ammonia yang mampu meningkatkan pH pada air umpan boiler. Dalam penelitian ini dilakukan penentuan kebutuhan injeksi ammonia untuk meningkatkan $\mathrm{pH}$ pada air umpan boiler. Metode yang digunakan adalah pengumpulan data primer langsung dari pabrik, analisa $\mathrm{pH}$ sampel dengan $\mathrm{pH}$ meter dan penentuan kebutuhan ammonia dengan perhitungan stoikiometri. Dari analisa dan perhitungan diperoleh hasil bahwa rata-rata kebutuhan ammonia yang sesuai standar pabrik untuk meningkatkan $\mathrm{pH}$ air umpan boiler adalah 0,0843 Kg/jam dengan rentang $\mathrm{pH} 9,2-$ 9,53. Semakin tinggi frekuensi bukaan pompa maka kenaikan $\mathrm{pH}$ air umpan boiler semakin turun.
\end{abstract}

Kata kunci: Air Umpan Boiler, Ammonia, $p H$

\section{Determination of Needs for Ammonia Injection to Increase pH in Boiler Feed Water: A Case Study at PT. XYZ North Sumatra}

\begin{abstract}
Boiler feed water at PT. XYZ comes from sea water. The processing of seawater into boiler feed water goes through several stages with the aim of removing impurities, salinity, ions, and dissolved gases in seawater. One of the parameters for the quality of boiler feed water which has a $\mathrm{pH}$ with plant standards of 9.2-9.6. $\mathrm{pH}$ that does not meet plant standards can cause corrosion of pipes and boilers. To achieve a $p H$ that is in accordance with plant standards, further treatment must be carried out in the form of adding ammonia which can increase the $\mathrm{pH}$ in boiler feed water. In this study, the determination of needs for ammonia injection was carried out to increase the $\mathrm{pH}$ in boiler feed water. The method used was the collection of primary data directly from the plant, analysis of $\mathrm{pH}$ samples with a $\mathrm{pH}$ meter and determination of ammonia requirements with stoichiometric calculations. From the analysis and calculations, it was revealed that the average ammonia requirement according to plant standards to increase the $\mathrm{pH}$ of boiler feed water was $0.0843 \mathrm{Kg} / \mathrm{hour}$ with a pH range of 9.2 9.53. The higher the pump opening frequency, the lower the $\mathrm{pH}$ elevation of the boiler feed water.
\end{abstract}

Keywords: Boiler Feed Water, Ammonia, $\mathrm{pH}$

\section{PENDAHULUAN}

Ketel uap atau istilah pabrik (plant) disebut juga dengan boiler merupakan bejana yang digunakan sebagai tempat untuk memproduksi uap (steam) sebagai hasil pemanasan air pada suhu tertentu untuk nantinya dipakai lebih lanjut diluar bejana tersebut [1]. Sumber energi yang umum digunakan pabrik untuk boiler adalah batu bara [2]. Air umpan adalah air yang disuplai ke boiler untuk diubah menjadi steam. Sedangkan sistem air umpan adalah sistem penyediaan air secara otomatis untuk boiler sesuai dengan kebutuhan sistem. Air umpan boiler harus memenuhi persyaratan tertentu untuk menghindari kerusakan pada boiler [3]. 
PT. XYZ adalah sebuah anak perusahaan PLN yang menjalankan usaha komersial pada bidang pembangkit tenaga listrik uap dengan memanfaatkan air laut sebagai bahan utama dalam prosesnya dan berlokasi di provinsi Sumatera Utara. Pengolahan air laut menjadi air umpan boiler harus melewati beberapa tahapan yaitu pretreatment, desalinasi, demineralisasi dan dearasi. Hal ini dilakukan agar air umpan boiler memenuhi persyaratan tertentu untuk menghindari kerusakan pada boiler. Air umpan sendiri adalah air yang disuplai ke boiler untuk diubah menjadi steam. Sedangkan sistem air umpan adalah sistem penyediaan air secara otomatis untuk boiler sesuai dengan kebutuhan sistem. Secara umum air yang akan digunakan sebagai air umpan boiler adalah air yang tidak mengandung unsur yang dapat menyebabkan terjadinya endapan yang dapat membentuk kerak pada boiler, air yang tidak mengandung unsur yang dapat menyebabkan korosi terhadap boiler dan sistem penunjangnya dan juga tidak mengandung unsur yang dapat menyebabkan terjadinya pembusaan terhadap air boiler [4].

Ammonia $\left(\mathrm{NH}_{3}\right)$ merupakan jenis nitrogen yang penting alam sekitar. Ammonia dapat larut dengan mudah di dalam air dan menjadi ion ammonium $\left(\mathrm{NH}_{4}{ }^{+}\right)$[5]. Ammonia berperan dalam penting dalam konsep kimia asam-basa dimana dapat menetralkan kondisi asam di lingkungan dan mempertahankan keseimbangan ekosistem lingkungan [6]. Ammonia juga dapat bersifat racun bagi lingkungan seperti adanya kandungan ammonia pada air kemasan botol minuman [7], dapat menyerap air membentuk ammonia water yang dapat melarutkan protein jaringan tubuh dan terjadi saponifikasi lemak dan mengganggu sistem metabolisme tubuh [8]. Penentuan adanya kandungan ammonia dan kadarnya dalam suatu sampel air dilakukan dengan beberapa reagen pereaksi menggunakan spektrofotometer UV-Vis [9]-[11].

Pada skala pabrik, ammonia berfungsi untuk menaikkan $\mathrm{pH}$ pada air umpan. Dosis ammonia bertujuan untuk menjaga kualitas pH berkisar antara 9,2-9,6. Injeksi ammonia bertujuan untuk mencegah terjadinya korosi, penskalan, dan deposisi garam pada pipa yang dilaluinya dan boiler. Injeksi ammonia yang berlebih atau melewati batasan ke air umpan dapat mengakibatkan terjadinya scaling di dalam pipa-pipa dan boiler sehingga dapat menyebabkan korosi [4]. Penambahan ammonia harus disesuaikan dengan kebutuhan dalam air umpan boiler sehingga diperlukan adanya analisis dan perhitungan terhadap banyaknya ammonia yang dapat menaikkan $\mathrm{pH}$ air umpan boiler. Tujuan penelitian ini dilakukan adalah untuk mendapatkan informasi kuantitatif terhadap kebutuhan ammonia yang dialirkan saat injeksi pada air umpan boiler sehingga $\mathrm{pH}$ air umpan menjadi naik dan menjadi air umpan yang bersifat basa.

\section{METODE PENELITIAN}

Penelitian diawali dengan mengumpulkan data primer dari pabrik PT. XYZ khususnya pada unit Boiler yang meliputi data laju alir air umpan sebelum injeksi dan data bukaan pompa ammonia. Data ini diambil pada saat pabrik beroperasi selama tiga hari berturut-turut.

\subsection{Alat dan Bahan}

Alat yang digunakan meliputi pompa tangki amoniak, gelas beaker $100 \mathrm{~mL}$, HK-3C Benchotop pH meter dan batang pengaduk. Bahan yang digunakan meliputi air umpan sebelum dan sesudah injeksi dengan ammonia, ammonia $2 \%(\mathrm{v} / \mathrm{v})$ dari tanki ammonia dan akuades.

\subsection{Analisa pH Air Umpan}

Air umpan boiler sebelum dan sesudah injeksi dengan ammonia diambil dan dimasukkan ke dalam gelas beaker. Kemudian air tersebut diaduk dengan batang pengaduk. Alat HK-3 Benchotop pH meter dihidupkan, lalu katoda dicelupkan kedalam akuades. Selanjutnya katoda dicelupkan ke dalam air umpan masing-masing sebelum dan setelah injeksi untuk diukur pHnya dan biarkan stabil selama 1-2 menit. Lalu diamati dan dicatat nilai pHnya.

\subsection{Stoikiometri Massa Ammonia}

Analisa kebutuhan ammonia yang diinjeksi dapat ditentukan dengan perhitungan stoikiometri. Besarnya $\mathrm{pH}$ air umpan boiler yang terukur setelah injeksi dengan ammonia kemudian dihitung konsentrasi ion hidroksida $\left[\mathrm{OH}^{-}\right]$yang terbentuk dengan persamaan :

$$
\left[O H^{-}\right]=10^{-(p K w-p H)}
$$


Selanjutnya massa ammonia ( $\mathrm{Kg} / \mathrm{jam})$ yang diinjeksikan ditentukan dengan persamaan :

$$
\text { massa ammonia }=\left[\mathrm{OH}^{-}\right] \times \mathrm{V} \times \mathrm{BM}
$$

dengan $\mathrm{V}$ adalah laju alir air umpan boiler (L/jam) dan BM adalah berat molekul $\mathrm{NH}_{3}(17 \mathrm{~g} / \mathrm{mol})$.

\section{HASIL DAN PEMBAHASAN}

Kebutuhan energi dan sistem pemanasan dalam industri umumnya dipenuhi dengan cara memanfaatkan steam yang dibangkitkan dalam suatu ketel (boiler). Air yang berasal dari air laut tidak dapat langsung digunakan untuk air umpan boiler. Air yang digunakan harus diolah terlebih dahulu, karena jika tidak, maka masa pakai boiler akan berkurang. Pengolahan air sebelum masuk ke boiler sering disebut sebagai external treatment. Di samping itu, air yang sudah diolah setelah masuk boiler pun harus mendapatkan perlakuan lagi di dalam ketel (internal treatment) [12].

Data primer yang diperoleh dari pabrik dengan tiga kali pengamatan selama tiga hari berturut-turut meliputi laju alir air umpan boiler dan frekuensi bukaan pompa tanki ammonia. Pengamatan dilakukan dengan memperhatikan kondisi mesin yang sama dan wawancara lisan dengan teknisi operator. Data primer yang disajikan pada tabel 1 menunjukkan bahwa semakin tinggi frekuensi bukaan pompa tanki ammonia maka semakin rendah laju alir air umpan boiler.

Tabel 1. Data Primer Air Umpan Boiler

\begin{tabular}{ccc}
\hline Sampel Air Umpan & Laju Alir Air Umpan Boiler $\left(\mathbf{m}^{\mathbf{3}} / \mathbf{j a m}\right)$ & Bukaan Pompa (Hz) \\
\hline Hari pertama & 202,13 & 20 \\
Hari kedua & 202,10 & 25 \\
Hari ketiga & 202,06 & 30 \\
\hline
\end{tabular}

Tabel 2. pH Air Umpan Boiler Sebelum dan Sesudah Injeksi Ammonia

\begin{tabular}{cccc}
\hline \multirow{2}{*}{ Sampel Air Umpan } & \multicolumn{2}{c}{$\mathbf{p H}$} & \multirow{2}{*}{ Kenaikan pH } \\
\cline { 2 - 3 } & Sebelum & Sesudah & \\
\hline Hari pertama & 6,5 & 9,20 & 2,7 \\
Hari kedua & 6,7 & 9,38 & 2,68 \\
Hari ketiga & 7,0 & 9,53 & 2,53 \\
\hline
\end{tabular}

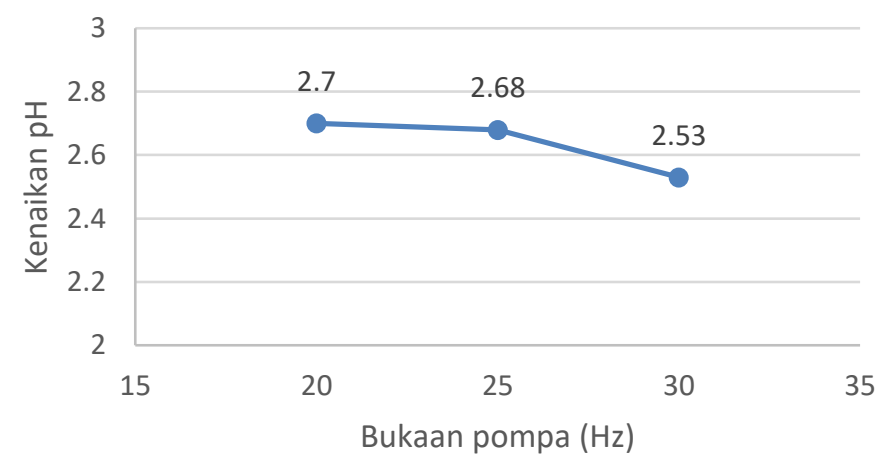

Gambar 1. Profil bukaan pompa terhadap kenaikan $\mathrm{pH}$

Selanjutnya air umpan boiler dilakukan analisa terhadap $\mathrm{pH}$ air pada keadaan sebelum dan sesudah injeksi dengan ammonia. Hasil analisa $\mathrm{pH}$ dengan $\mathrm{pH}$ meter digital ditunjukkan pada tabel 2. Nilai $\mathrm{pH}$ air umpan boiler sebelum dan sesudah injeksi bervariasi pada pengamatan hari pertama, kedua dan ketiga. Nilai kenaikan $\mathrm{pH}$ ini mengalami penurunan mulai dari hari pertama hingga hari ketiga dikarenakan nilai bukaan pompa juga meningkat di hari pengamatan. Nilai pH air umpan boiler ini sebenarnya masih dibawah nilai standar air umpan boiler menurut standar American Society Of Mechanical Engineers (ASME) dimana berkisar antara 10,5-11,5 [13]. Ammonia yang diinjeksikan pada air umpan boiler bersifat alkalinitas dimana gambaran kapasitas air ammonia untuk menetralkan asam atau dikenal dengan sebutan acid-neutralizing capacity (ANC) atau kuantitas anion di dalam air yang dapat menetralkan kation hidrogen sehingga $\mathrm{pH}$ air menjadi naik [14]. Semakin tinggi 
nilai frekuensi bukaan pompa tanki ammonia maka semakin turun nilai kenaikan $\mathrm{pH}$ air umpan boiler yang ditunjukkan pada gambar 1.

Lebih lanjut hasil pH air umpan boiler ini dan data primer kemudian dianalisis dengan prinsip stoikiometri untuk menentukan massa ammonia yang diinjeksikan sehingga dapat meningkatkan $\mathrm{pH}$. Hasil perhitungan stoikiometri ditunjukkan pada tabel 3. Rata-rata massa ammonia yang diinjeksikan pada air umpan boiler sehingga dapat meningkatkan $\mathrm{pH}$ dengan rentang $\mathrm{pH}$ naik menjadi 9,2-9,53 adalah sebesar 2,4573 x10-5 mol/L atau sama dengan $0,0843 \mathrm{Kg} / \mathrm{jam}$ dari konsentrasi total ammonia pada tanki sebanyak $2 \%(\mathrm{v} / \mathrm{v})$.

Tabel 3. Tabulasi Data Penentuan Kebutuhan Ammonia

\begin{tabular}{cccccc}
\hline $\begin{array}{c}\text { Sampel Air } \\
\text { Umpan }\end{array}$ & $\begin{array}{c}\text { Laju Alir Air } \\
\text { Umpan Boiler } \\
\left(\mathbf{m}^{3} / \text { jam }\right)\end{array}$ & $\begin{array}{c}\text { Bukaan } \\
\text { Pompa }(\mathbf{H z})\end{array}$ & $\begin{array}{c}\text { Kenaikan } \\
\mathbf{~ p H}\end{array}$ & $\begin{array}{c}\text { Konsentrasi NH3 } \\
\text { setelah Injeksi } \\
(\mathbf{m o l} / \text { Liter })\end{array}$ & $\begin{array}{c}\text { Massa NH3 yang } \\
\text { dinjeksikan } \\
(\text { Kg/Jam })\end{array}$ \\
\hline Hari pertama & 202,13 & 20 & 2,7 & 0,000015848 & 0,0544 \\
Hari kedua & 202,10 & 25 & 2,68 & 0,000023988 & 0,0824 \\
Hari ketiga & $\begin{array}{c}202,06 \\
\text { Rata-rata }\end{array}$ & 30 & 2,53 & 0,000033884 & 0,1163 \\
& & & 0,000024573 & 0,0843 \\
\hline
\end{tabular}

\section{KESIMPULAN}

Melalui analisa dan perhitungan yang telah dilakukan maka dapat disimpulkan bahwa dengan adanya kenaikan nilai frekuensi bukaan pompa maka kenaikan nilai $\mathrm{pH}$ dan laju alir air umpan boiler menjadi semakin turun. Adapun rata-rata kebutuhan injeksi ammonia melalui pengamatan dan pengambilan sampel selama tiga hari berturut-turut menunjukkan bahwa sebanyak $0,0843 \mathrm{Kg} / \mathrm{jam}$ dapat meningkatkan $\mathrm{pH}$ air umpan boiler dengan rentang $\mathrm{pH}$ 9,2-9,53.

\section{DAFTAR PUSTAKA}

[1] A. Irawan, S. Heranurweni, and T. Nurhayati, "Simulasi Ph Air Untuk Air Boiler Dan Air Chiller Pada Mesin Produksi Refrigerator Dengan Menggunakan Logika Fuzzy,” Elektrika, vol. 11, no. 1, p. 26, 2019, doi: 10.26623/elektrika.v11i1.1541.

[2] D. F. Simatupang, Yunianto, and E. D. W. Sihaloho, “Analisa Kebutuhan Batu Bara pada Unit Dryer dalam Pengeringan Pupuk NPK di PT AGS Medan,” CHEESA Chem. Eng. Res. Artic., vol. 4, no. 1, pp. 11-17, 2021, doi: 10.25273/cheesa.v4i1.7830.11-17.

[3] Rahayu, Y. Amri, and T. Harmawan, "Analisis pH dan Kesadahan Total pada Air Umpan Boiler di PMKS PT. SISIRAU Aceh Tamiang,” Quim. J. Kim. Sains dan Terap., vol. 1, no. April, pp. 1-4, 2019.

[4] PT. XYZ, "Modul Water Treatment Plant," Sumatera Utara, 2019.

[5] A. Abdel, M. S. El, and A. O. Abdelhamid, "European Journal of Chemistry," Eur. J. Chem., vol. 3, no. 4, pp. 455-460, 2012, doi: 10.5155/eurjchem.3.3.359.

[6] J. Yang, Y. Jiao, W. Z. Yang, P. Gu, S. G. Bai, and L. J. Liu, "Review of methods for determination of ammonia volatilization in farmland," IOP Conf. Ser. Earth Environ. Sci., vol. 113, no. 1, 2018, doi: 10.1088/1755-1315/113/1/012022.

[7] A. Sasongko, R. W. Nugroho, and D. Mulyani, “Ammonia Determination In Bottled Water Using Spectrophotometer: Comparison Between Nessler And Berthelot Methods," JST (Jurnal Sains dan Teknol., vol. 7, no. 1, p. 126, 2018, doi: 10.23887/jst-undiksha.v7i1.13009.

[8] M. Sui, Y. Guan, C. Qiu, J. Li, K. Zhu, and J. Hu, "Improvement of Determination Method of Ammonia in Indoor Air and Analysis of Monitoring Results," IOP Conf. Ser. Earth Environ. Sci., vol. 252, no. 4, 2019, doi: 10.1088/1755-1315/252/4/042088.

[9] M. Azizah and M. Humairoh, "Analisa Kadar Amonia (NH3) Dalam Air Sungai Cileungsi,” Nusa Sylva, vol. 15, no. 82, pp. 47-54, 2015.

[10] K. Ngibad, "Penentuan konsentrasi ammonium dalam air Sungai Pelayaran Ngelom," J. Med. Lab. Sci. Technol., vol. 2, no. 1, pp. 37-42, 2019, doi: 10.21070/medicra.v2i1.2071.

[11] P. M. Yogi, "Penentuan Kadar Ammonia ( NH 3 ) pada Limbah Cair K-36 dalam Rangka Pengendalian 
Pencemaran Lingkungan Alat dan Bahan,” Ilmu Kim. dan Terap., vol. 2, no. 2, pp. 22-26, 2018.

[12] Budiyono and S. Sumardiono, Teknik Pengolahan Air. Semarang: Graha Ilmu, 2013.

[13] M. Fatimura, "Study Analisa Kualitas Air Boiler Menggunakan Standar American Society Of Mechanical Engineers," Universitas PGRI Palembang, 2016.

[14] H. Effendi, Telaah Kualitas Air Bagi Pengolahan Sumber Daya dan Lingkungan Perairan, Cetakan 5. Yogyakarta: Kanisius, 2003. 